\title{
Study the therapeutic role of transcranial magnetic stimulation in a sample of Egyptian patients with resistant obsessive-compulsive disorder
}

\author{
Ahmed Saadeldin Abdel Alim ${ }^{1}$ MSc; Abd El Hady Essa Hasan ${ }^{1}$ MD; Mohamed Ahmed Kamal ${ }^{1}$ MD;Amgad \\ Ahmed Gabr ${ }^{1}$ MD; Mohamed Ahmed Abozed ${ }^{1}$ MD
}

* Corresponding Author:

Ahmed Saadeldin Abdel Alim ahmed.eldain@gmail.com

Received for publication March 24, 2020; Accepted June 7, 2020; Published online September 5, 2020.

Copyright 2020 The Authors published by Al-Azhar University, Faculty of Medicine, Cairo, Egypt. All rights reserved. This an open-access article distributed under the legal terms, where it is permissible to download and share the work provided it is properly cited. The work cannot be changed in any way or used commercially.

doi: $10.21608 /$ aimj.2020.26505.1181

${ }^{1}$ Psychiatry Department, Al-Azhar University, Faculty of Medicine, AlAzhar University, Cairo, Egypt.

\begin{abstract}
Background: Obsessive-compulsive disorder (OCD) is a debilitating neuropsychiatric disorder that affects approximately $2-3 \%$ of the world population. The first-line treatments are selective serotonin reuptake inhibitors and cognitive behavioral therapy. Despite that, approximately $40-60 \%$ of patients remain treatment refractive.

Aim of work: Evaluating the efficacy of different frequencies of repetitive transcranial magnetic stimulation (rTMS) applied over the right dorsolateral prefrontal cortex (DLPFC) as an adjunctive treatment for resistant OCD.

Patient and Methods: Thirty patients with treatment resistant OCD were randomly assigned to 2 weeks either active $\mathrm{LF}(1 \mathrm{~Hz}, \mathrm{n}=10)$, HF $(10 \mathrm{~Hz}, \mathrm{n}=10)$ with parameters $(25$-minute trains, 1,500 pulses/day at $100 \%$ of the resting motor threshold RMT, 5 sessions/week) or sham $(\mathrm{n}=10)$ (same HF parameters with coil tilting). OCD, anxiety and depressive symptoms were assessed using: Yale-Brown Obsessive Compulsive Scale (Y-BOCS), Hamilton Anxiety Scale (HAM-A), Beck Depression Inventory (BDI) and Clinical Global Impression-Severity scale (CGI-S) before and immediately after sessions and 3 months later. Results: A repeated-measures analysis of variance (ANOVA) revealed a non-significant reduction in Y-BOCS scores in the active groups compared with the sham group after 2 weeks and 3 months later. Similarly, there was non-significant effect of time and timexgroup interaction on scores of (HAM-A) (CGI-S). While there was a significant effect of time and timexgroup interaction on scores of (BDI) after 2 weeks with active stimulation especially LF-rTMS not after 3 months. There were no reports of serious adverse effects following the active or sham rTMS treatments.

Conclusion: Neither LF nor HF rTMS over the right DLPFC appeared to be superior to sham rTMS for relieving OCD and anxiety symptoms in patients with treatment-resistant OCD. However, rTMS has a role in improving depressive symptoms, especially with LF-rTMS. Further trials with larger sample sizes should be conducted to confirm the present findings.

Keywords: Transcranial magnetic stimulation; Obsessive-compulsive disorder; Dorsolateral prefrontal cortex.
\end{abstract}

Disclosure: The authors have no financial interest to declare in relation to the content of this article. The Article Processing Charge was paid for by the authors.

Authorship: All authors have a substantial contribution to the article.

\section{INTRODUCTION}

Obsessive-compulsive disorder (OCD) is a chronic and highly debilitating neuropsychiatric disorder characterized by obsessions and/ or compulsions; that lead to significant distress to the patients and their families. ${ }^{1}$

Obsessions are persistent, intrusive ego dystonic thoughts, urges or images, while compulsions are repetitive and time-consuming behaviors or mental acts that usually done to prevent the occurrence or limit the distress caused by the obsession. ${ }^{2}$
The prevalence of OCD in the general population is estimated at 2 to $3 \%$, and it affects both sexes equally. ${ }^{3}$

High doses of SSRIs and clomipramine in addition to $\mathrm{CBT}$ are considered as first-line treatments for OCD at present. ${ }^{4}$

Recently, treatment regimens have expanded to include other psychotropic drugs, particularly antipsychotics. ${ }^{5}$

Despite that, $40-60 \%$ of patients fail to respond to those medications appropriately or unable to tolerate their side effects. ${ }^{6}$ 
Therefore, it was important to develop new treatment strategies based on understanding the abnormalities that contribute to OCD. ${ }^{7}$

Repetitive Transcranial Magnetic Stimulation (rTMS) is one of the potential additional treatments for OCD. It is a non-invasive neuromodulator technique in which strong electrical currents are passed through a coil that is placed directly on the scalp to induce magnetic field pulses with sufficient intensity able to pass through the skull and form an electrical current in the cortical region below the coil; consequently, depolarizing or hyperpolarizing the axons of the neurons. ${ }^{8}$

Although pathophysiology of OCD is not fully understood, many studies suggested that OCD is associated with dysfunction in the orbitofronto striato- pallido-thalamic circuitry. This includes dorsolateral prefrontal cortex (DLPFC), anterior cingulate gyrus, supplementary motor area (SMA), orbitofrontal cortex (OFC) and caudate nucleus. Among those structures, the DLPFC is the most suitable site for rTMS due to its superficial location. However, there were only few studies that applied rTMS over DLPFC region for the treatment of OCD, and they have given conflicting results. ${ }^{9}$

The aims of the present study are evaluating the therapeutic effect of the different frequencies of rTMS $(1 \mathrm{~Hz}, 10 \mathrm{~Hz})$ applied over the right-DLPFC versus sham stimulation in the treatment of OCD patients.

\section{PATIENT AND MATERIALS}

The present study has included 30 patients with a primary diagnosis of OCD according to DSM-5 criteria from those attending psychiatric clinic at Sayed Galal Hospital, Faculty of Medicine, Al-Azhar University and accepted to participate in this study by obtaining prior informed consent during the period from February 2019 to December 2019. The ethical Committee of the Faculty of Medicine, AlAzhar University approved the experimental protocol.

Inclusion criteria:

Patients aged from 18 to 65 years old of both sexes with Yale-Brown Obsessive Compulsive Scale (YBOCS) score: $\geq 16$ and failed to achieve an appropriate response after 3 separate trials with sufficient doses of antidepressants for at least 12 weeks

Exclusion criteria:

Patients with history of other comorbid neuropsychiatric disorder; drug abuse, history of epilepsy, serious head injury or neurosurgical procedure; metal implants and pacemakers.

Procedure:

The stimulation was carried out using an 8-figure shape coil (Magstim rapid2), which placed with its center Parallel above the optimal position of the Right DLPFC.

The right DLPFC was identified by measuring $5 \mathrm{~cm}$ anterior to and in the parasagittal line from the point of the maximum stimulation of the left abductor pollicis brevis (APB) muscle. The Resting Motor
Threshold (RMT) has been determined using visualization method via the stimulation of the primary motor cortex area for APB muscle in 5 successful trials of 10 TMS.

The patients were randomly classified into three groups to receive either a sham or active LF\& HF rTMS. The 1st group: included 10 patients received rTMS with $(1 \mathrm{~Hz}$ frequency, 1500 pulses/session at $100 \%$ of RMT applied in 150 trains, with 5 seconds inter-train interval). The 2nd group: included 10 patients received $(10 \mathrm{~Hz}$ rTMS, 1500 pulses/ session, $100 \%$ of RMT applied in 30 trains, with 45 seconds inter-train interval). The 3rd (sham) group: included 10 patients received stimulation with the same parameters of the 2nd group and the coil was placed over the same area but perpendicular to the scalp.

Every patient received 10 sessions, each session lasting 25 minutes, 1 session/ day for 5 consecutive days for two weeks and continued pharmacological treatments with the same doses throughout the study. Neither the patient nor the rater knew whether the patients were receiving real or sham rTMS.

All patients were assessed before rTMS procedure, after 2 weeks and 3 months later with Yale-Brown obsessive compulsive scale (Y-BOCS)10, Hamilton anxiety rating scale (HAM-A)11, Beck Depression Inventory (BDI) 12 and Clinical global impressionseverity scale (CGI-S). 13

Statistical analysis:

Data was analyzed using SPSS version 23.0. Quantitative data were expressed as mean \pm standard deviation (SD). Qualitative data were expressed as percentage. The demographic and clinical data were compared using t-tests, chi-square tests. A repeatedmeasures analysis of variance (ANOVA) was used to evaluate the group- and time-dependent effects of rTMS on the mean scores of the psychometric scales. Patients with a reduction $\geq 25 \%$ in Y-BOCS score were classified as responders. $\mathrm{P}$ value $<0.05$ was considered to indicate statistical significance.

\section{RESULTS}

Of the 36 patients who were initially included in this study, 6 cases were excluded prior to the start of the treatment because they weren't consistent with the inclusion criteria. Therefore, the final sample consisted of 30 patients: 10 patients in each group. All patients completed treatment sessions, and the procedure was well tolerated.

The difference between the active and the sham groups according to demographic data wasn't statistical significant. Table (1).

As regard OCD symptoms according to Y-BOCS, there is mild reduction in the 3 groups immediately after sessions and 3 months later but without statistical significant difference Table (2-a). The comparison between 3 groups according to mean YBOCS isn't significantly different neither immediately after sessions $(\mathrm{F}=1.068, \mathrm{P}=0.358)$ nor 3 months later $(\mathrm{F}=2.107, \mathrm{P}=0.141)$ Table $(2-\mathrm{b})$.

There is mild reduction in 
HAM-A after 2 weeks and 3 months in the 3 groups without statistical significant difference Table (3-a). The difference between groups according to mean HAM-A isn't significant either after 2 weeks $(\mathrm{F}=0.258, \mathrm{P}=0.774)$ or 3 months later $(\mathrm{F}=0.294$, $\mathrm{P}=0.748$ ) Table (3-b).

As regard depressive symptoms according to BDI, there is highly significant reduction after 2 weeks in Group I (HZ1) $(\mathrm{p}=<0.001 *)$ but not after 3 months $(\mathrm{p}=0.155)$, also there is significant reduction after 2 weeks in Group II (HZ10) ( $\left.\mathrm{p}=0.008^{*}\right)$ but not after 3 months $(p=0.096)$, while in the sham group there is mild reduction after 2 weeks and 3 months without statistical significant difference (Table $4-$ a). The comparison between groups according to mean BDI was significantly different after 2 weeks only $(\mathrm{F}=4.790, \mathrm{P}=0.017 *)$ Table $(4-\mathrm{b})$.

There is mild reduction in CGI-S after 2 weeks and 3 months without statistical significant difference Table $(5-a)$. The comparison between groups according to mean CGI-S isn't significantly different neither after 2 weeks $(\mathrm{F}=0.568, \mathrm{P}=0.573)$ nor after 3 months $(\mathrm{F}=0.333, \mathrm{P}=0.719)$ Table $(5-\mathrm{b})$.

\begin{tabular}{|c|c|c|c|c|c|c|}
\hline \multicolumn{2}{|c|}{ Variable } & $\begin{array}{c}\text { 1HZ group } \\
(\mathrm{n:10})\end{array}$ & $\begin{array}{c}10 \mathrm{HZ} \text { group } \\
(\mathrm{n}: 10)\end{array}$ & $\begin{array}{c}\text { Sham group } \\
(\mathrm{n}: 10)\end{array}$ & $\mathrm{X}^{2}$ & p-value \\
\hline Age (years) & Mean \pm SD & $30.0 \pm 6.88$ & $28.7 \pm 5.44$ & $30.9 \pm 8.48$ & $\begin{array}{c}\text { ANOV } \\
\mathrm{A}= \\
0.247\end{array}$ & $0.783^{\mathrm{NS}}$ \\
\hline \multirow[t]{2}{*}{ Sex } & Male & $7(70 \%)$ & $6(60 \%)$ & $4(40 \%)$ & \multirow[b]{2}{*}{1.900} & \multirow[b]{2}{*}{$0.387^{\mathrm{NS}}$} \\
\hline & Female & $3(30 \%)$ & $4(40 \%)$ & $6(60 \%)$ & & \\
\hline \multirow[t]{2}{*}{ Marital status } & Married & $5(50 \%)$ & $3(30 \%)$ & $4(40 \%)$ & \multirow[b]{2}{*}{0.833} & \multirow[b]{2}{*}{$0.659^{\mathrm{NS}}$} \\
\hline & Single & $5(50 \%)$ & $7(70 \%)$ & $6(60 \%)$ & & \\
\hline \multirow[t]{2}{*}{ Occupation } & Work & $4(40 \%)$ & $5(50 \%)$ & $3(30 \%)$ & \multirow[b]{2}{*}{0.833} & \multirow[b]{2}{*}{$0.659 \mathrm{NS}$} \\
\hline & No work & $6(60 \%)$ & $5(50 \%)$ & $7(70 \%)$ & & \\
\hline \multirow[t]{2}{*}{ Handedness } & Right & $9(90 \%)$ & $8(80 \%)$ & $9(90 \%)$ & \multirow[b]{2}{*}{0.577} & \multirow[b]{2}{*}{$0.749^{\mathrm{NS}}$} \\
\hline & Left & $1(10 \%)$ & $2(20 \%)$ & $1(10 \%)$ & & \\
\hline
\end{tabular}

Table 1: Demographic data of the studied patients

NS There is no significant statistical difference.

$\mathrm{X}^{2}$ : Chi square test.

\begin{tabular}{|c|c|c|c|c|c|}
\hline \multirow[t]{2}{*}{ Y-BOCS } & $\begin{array}{l}\text { Before } \\
\text { session }\end{array}$ & $\begin{array}{c}\text { Immediately } \\
\text { after }\end{array}$ & After 3 months & \multirow[t]{2}{*}{$\mathbf{p}_{1}$} & \multirow[t]{2}{*}{$\mathbf{p}_{2}$} \\
\hline & SD. \pm Mean & SD. \pm Mean & SD. \pm Mean & & \\
\hline Group I (HZ1) & $2.92 \pm 28.90$ & $5.36 \pm 25.70$ & $4.33 \pm 26.40$ & $\begin{array}{l}0.057 \\
\text { (NS) }\end{array}$ & $0.056(\mathrm{NS})$ \\
\hline Group II (HZ10) & $2.97 \pm 29.20$ & $3.85 \pm 26.80$ & $3.53 \pm 28.30$ & $\begin{array}{c}0.243 \\
\text { (NS) }\end{array}$ & $0.440(\mathrm{NS})$ \\
\hline Group III (Sham) & $3.35 \pm 30.10$ & $4.09 \pm 28.60$ & $3.54 \pm 29.90$ & $\begin{array}{c}0.214 \\
\text { (NS) }\end{array}$ & $1.000(\mathrm{NS})$ \\
\hline
\end{tabular}

Table 2-a: Y-BOCS before and after sessions. p1: p-value (before session and immediately after) p2: p-value (before session and after 3 month) NS: Not significant

\begin{tabular}{r|c|c|c|c|c|}
\hline Y-BOCS & Group I (HZ1) & Group II (HZ10) & Group III (Sham) & F & P-value \\
\hline Before session & $2.92 \pm 28.90$ & $2.97 \pm 29.20$ & $3.35 \pm 30.10$ & 0.409 & 0.668 (NS) \\
\hline Immediately after & $5.36 \pm 25.70$ & $3.85 \pm 26.80$ & $4.09 \pm 28.60$ & 1.068 & $\begin{array}{l}0.358 \\
\text { (NS) }\end{array}$ \\
\hline After 3 months & $4.33 \pm 26.40$ & $3.53 \pm 28.30$ & $3.54 \pm 29.90$ & 2.107 & $\begin{array}{l}0.141 \\
(\mathrm{NS})\end{array}$ \\
\hline
\end{tabular}

Table 2-b: Mean Y-BOCS before and after sessions F: F for ANOVA test NS: Not significant 


\begin{tabular}{|c|c|c|c|c|c|}
\hline \multirow[t]{2}{*}{ HAM-A } & $\begin{array}{l}\text { Before } \\
\text { session }\end{array}$ & $\begin{array}{c}\text { Immediately } \\
\text { after }\end{array}$ & $\begin{array}{l}\text { After } 3 \\
\text { months }\end{array}$ & p1 & $\mathbf{p}_{2}$ \\
\hline & $\mathrm{SD} \pm$ Mean & $\mathrm{SD} \pm$ Mean & $\mathrm{SD} \pm$ Mean & & \\
\hline Group I (HZ1) & $6.28 \pm 32.40$ & $9.51 \pm 27.60$ & $8.52 \pm 29.80$ & $\begin{array}{l}0.084 \\
\text { (NS) }\end{array}$ & $\begin{array}{l}0.172 \\
\text { (NS) }\end{array}$ \\
\hline Group II (HZ10) & $6.72 \pm 33.60$ & $8.59 \pm 30.30$ & $7.64 \pm 32.0$ & $\begin{array}{l}0.066 \\
\text { (NS) }\end{array}$ & $\begin{array}{l}0.110 \\
\text { (NS) }\end{array}$ \\
\hline Group III (Sham) & $6.63 \pm 34.0$ & $7.97 \pm 29.60$ & $6.44 \pm 32.10$ & $\begin{array}{l}0.066 \\
\text { (NS) }\end{array}$ & $\begin{array}{l}0.082 \\
\text { (NS) }\end{array}$ \\
\hline
\end{tabular}

Table 3-a: HAM-A before and after sessions.

\begin{tabular}{|r|c|c|c|c|c|}
\hline HAM-A & Group I (HZ1) & Group II (HZ10) & Group III (Sham) & F & P-value \\
\hline Before session & $6.28 \pm 32.40$ & $6.72 \pm 33.60$ & $6.63 \pm 34.0$ & 0.162 & $\begin{array}{c}0.851 \\
\text { (NS) }\end{array}$ \\
\hline Immediately after & $9.51 \pm 27.60$ & $8.59 \pm 30.30$ & $7.97 \pm 29.60$ & 0.258 & $\begin{array}{c}0.774 \\
\text { (NS) }\end{array}$ \\
\hline After 3 months & $8.52 \pm 29.80$ & $7.64 \pm 32.0$ & $6.44 \pm 32.10$ & 0.294 & $\begin{array}{c}0.748 \\
\text { (NS) }\end{array}$ \\
\hline
\end{tabular}

Table 3-b: Mean HAM-A before and after sessions

\begin{tabular}{|c|c|c|c|c|c|}
\hline \multirow{2}{*}{ BDI } & $\begin{array}{c}\text { Before } \\
\text { session }\end{array}$ & $\begin{array}{c}\text { Immediately } \\
\text { after }\end{array}$ & $\begin{array}{c}\text { After 3 } \\
\text { months }\end{array}$ & p1 & p2 \\
\hline & SD. \pm Mean & SD. \pm Mean & SD. \pm Mean & \\
\hline Group I (HZ1) & $5.77 \pm 64.20$ & $10.12 \pm 48.30$ & $8.77 \pm 61.0$ & $<0.001^{*}$ & $\begin{array}{c}0.155 \\
\text { (NS) }\end{array}$ \\
\hline Group II (HZ10) & $5.13 \pm 64.60$ & $8.92 \pm 58.0$ & $6.92 \pm 61.80$ & $0.008^{*}$ & $\begin{array}{c}0.096 \\
\text { (NS) }\end{array}$ \\
\hline Group III (Sham) & $5.27 \pm 63.40$ & $5.86 \pm 58.90$ & $5.34 \pm 62.90$ & 0.065 & $\begin{array}{c}0.532 \\
\text { (NS) }\end{array}$ \\
\hline
\end{tabular}

Table 4-a: BDI before and after sessions.

\begin{tabular}{|l|c|c|c|c|c|}
\hline BDI & Group I (HZ1) & Group II (HZ10) & Group III (Sham) & F & P-value \\
\hline Before sessions & $64.20 \pm 5.77$ & $64.60 \pm 5.13$ & $63.40 \pm 5.27$ & 0.128 & 0.880 (NS) \\
\hline Immediately after & $48.30 \pm 10.12$ & $58.0 \pm 8.92$ & $58.90 \pm 5.86$ & 4.790 & $0.017^{*}$ \\
\hline After 3 months & $61.0 \pm 8.77$ & $61.80 \pm 6.92$ & $62.90 \pm 5.34$ & 0.178 & 0.838 (NS) \\
\hline
\end{tabular}

Table 4-b: Mean BDI before and after sessions.

* Significant at p-value $\leq 0.05$ 

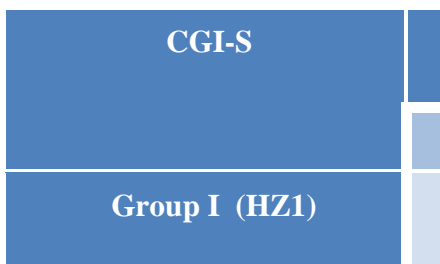

\begin{tabular}{|c|c|c|c|c|}
\hline $\begin{array}{c}\text { Before } \\
\text { session }\end{array}$ & $\begin{array}{c}\text { Immediately } \\
\text { after }\end{array}$ & $\begin{array}{c}\text { After 3 } \\
\text { months }\end{array}$ & p1 & p2 \\
\cline { 1 - 3 } SD. \pm Mean & SD. \pm Mean & SD. \pm Mean & & \\
\hline $0.63 \pm 4.80$ & $1.25 \pm 4.0$ & $0.97 \pm 4.40$ & $\begin{array}{r}0.067 \\
(\mathrm{NS})\end{array}$ & $\begin{array}{c}0.110 \\
(\mathrm{NS})\end{array}$ \\
\hline $0.57 \pm 4.90$ & $0.92 \pm 4.20$ & $0.84 \pm 4.60$ & $\begin{array}{r}0.075 \\
(\mathrm{NS})\end{array}$ & $\begin{array}{c}0.580 \\
(\mathrm{NS})\end{array}$ \\
\hline $0.67 \pm 5.0$ & $0.97 \pm 4.50$ & $0.67 \pm 4.70$ & $\begin{array}{c}0.157 \\
\text { (NS) }\end{array}$ & $\begin{array}{r}0.243 \\
(\mathrm{NS})\end{array}$ \\
\hline
\end{tabular}

Table 5-a: CGI-S before and after sessions.

\begin{tabular}{|r|c|c|c|c|c|}
\hline (CGI-S) & Group I (HZ1) & Group II (HZ10) & Group III (Sham) & F & p \\
\hline Before session & $0.63 \pm 4.80$ & $0.57 \pm 4.90$ & $0.67 \pm 5.0$ & 0.257 & $\begin{array}{c}0.775 \\
(\mathrm{NS})\end{array}$ \\
\hline Immediately after & $1.25 \pm 4.0$ & $0.92 \pm 4.20$ & $0.97 \pm 4.50$ & 0.568 & $\begin{array}{c}0.573 \\
\text { (NS) }\end{array}$ \\
\hline After 3 months & $0.97 \pm 4.40$ & $0.84 \pm 4.60$ & $0.67 \pm 4.70$ & 0.333 & $\begin{array}{c}0.719 \\
(\mathrm{NS})\end{array}$ \\
\hline
\end{tabular}

Table 5-b: CGI-S before and after sessions

\section{DISCUSSION}

The present study aimed to evaluate the effect of high and low frequencies of rTMS applied over the right DLPFC as an adjunctive treatment for resistant OCD comparing to sham TMS. This was in line with studies which indicated that rTMS of the right DLPFC was more effective for treating OCD than sham stimulation. ${ }^{14}$

The study included 30 OCD patients whom divided into a sham or active LF\& HF rTMS groups. The demographical and clinical data of the 3 groups were monitored at the baseline and there was no significant difference in the scores of Y-BCOS $(\mathrm{P}=$ $0.668)$, HAM-A $(\mathrm{P}=0.851)$, BDI $(\mathrm{P}=0.880)$ or CGI-S $(P=0.775) \quad($ Table $2 / 3 / 4 / 5-b)$. The side effects of the rTMS were acceptable as only one patient in HF-rTMS group complained of a mild headache which is consistent with what was mentioned in many previous studies. ${ }^{9}$

It was clear that OCD more common among males (56.66\% males) also most of the patients were in the third decade of life as the most representative age category in the three groups was (27-35 years) followed by (18-26 years) with the mean age in the 1 $\mathrm{HZ}$ group $30.0 \pm 6.88$, the $10 \mathrm{HZ}$ group $28.70 \pm 5.44$ and the sham group $30.90 \pm 8.48$. The difference between groups according to sex $(\mathrm{p}=0.387)$ and age ( $\mathrm{p}=0.783$ ) has no statistical significance Table (1).
This is consistent with Kang et al. study (17 males/ 3 females) with mean age (28.6), Sarkhel et al. (male/female 23/19), mean age (30.67) and many other studies which indicate that symptoms in more than $80 \%$ of casas started before the age of 35 Years. ${ }^{6}$

Regarding the marital and occupation status, the percentage of unmarried and non-workers people were higher in the 3 groups without statistical significance difference $(p=0.659)$. (Table 1) This can be explained by the presence of OCD as a mental disorder that causes a deterioration of social and occupational performance. ${ }^{7}$

Our result found that LF-rTMS $(1 \mathrm{~Hz})$ applied over Rt-DLPFC improves symptoms and severity of OCD measured by Y-BOCS and CGI-S also anxiety symptoms measured by HAM-A with mild degree of reduction in different scales at the end of the $2^{\text {nd }}$ week of treatment and only two patients were considered as responders to the treatment (defined as having decrease in the score of Y-BOCS $\geq 25 \%$ of the baseline) versus one patient in the HF-rTMS and the sham group. The difference between groups in YBOCS, HAM-A and CGI-S was not statistically significant either at the end of sessions or after 3 months (Table 2, 3, 5-a). ANOVA revealed a nonsignificant reduction in mean Y-BOCS, HAM-A and CGI-S after the sessions immediately 3 months later Table (2, 3, 5-b).

While LF-rTMS $(1 \mathrm{~Hz})$ has a great effect on symptoms of depression with a significant reduction of BDI score at the end of $2^{\text {nd }}$ week $\left(\mathrm{P}_{1}=<0.001\right)$ and 
symptoms disappeared in 4 patients versus 2 patients in the HF-rTMS group $(10 \mathrm{~Hz})$ and one patient in the sham group but after 3 months the difference was insignificant $\left(\mathrm{P}_{2}=0.155\right)$ Table (4-a). ANOVA revealed a significant reduction in mean BDI after 2 weeks but not after 3 months Table (4-b).

Our results are consistent with that of Alonso et al study, where they found that LF-rTMS over the right DLPFC failed to produce significant improvement of OCD $(p=0.081)$. Also results agreed with that of Kang et al. as there were no significant differences over 4 weeks between the active and sham groups on Y-BOCS $(\mathrm{F}=0.01, \mathrm{P}=0.92)$ HARS $(\mathrm{P}=0.84) .{ }^{15}$

While Seo et al. who studied the effect of LF-rTMS over Rt-DLPFC in 27 OCD for 3 weeks and there were statistically significant differences between the active and sham groups on Y-BOCS $(\mathrm{P}=0.008)$ at the end of the $3^{\text {rd }}$ week. Perhaps this is due to the difference in the stimulation period as well as the nature of sham stimulation. However, it is consistent with our results in its effect on depression and anxiety as there was a statistically significant difference on HAM-D starting from the $2^{\text {nd }}$ week, while there was no clear change between the two groups on HAM-A. ${ }^{9}$

In our study, there was also mild improvement in symptoms and severity of OCD after applying HFrTMS $(10 \mathrm{~Hz})$ over the Rt-DLPFC on Y-BOCS and CGI-S also anxiety symptoms on HAM-A, but it did not differ significantly from the effect of sham stimulation either at the end of sessions or after 3 months Table $(2,3,5$-a)

While HF-rTMS $(10 \mathrm{~Hz})$ had a modest effect on symptoms of depression with a significant reduction of BDI score at the end of $2^{\text {nd }}$ week $\left(\mathrm{P}_{1}=0.008\right)$ but without significance after 3 months $\left(\mathrm{P}_{2}=0.096\right)$ Table (4-a)

Our results are consistent with that of Sarkhel et al. who applied HF-rTMS over the Rt-DLPFC for 21 OCD patients versus sham rTMS for 21 patients with follow-up after 2 weeks, the results showed improvement in symptoms of OCD without significant difference $(\mathrm{F}=1.39, \mathrm{p}=.262)$. However, it is modestly effective in the treatment of comorbid depressive symptoms $(\mathrm{F}=3.67, \mathrm{p}=.035)$. It also agrees with the results of Mansur et al. study where they found that there was no significant difference in the Y-BOCS at the end of 6 weeks and $12^{\text {th }}$ week $(\mathrm{P}=$ $0.71) .{ }^{16,17}$

While our results differed from that of Greenberg et al. as they found that compulsion decreased significantly immediately after stimulating RtDLPFC $(\mathrm{P}<0.01)$ and remained significant after 8 hours $(\mathrm{P}<0.02)$. However, the effect was time limited, and the obsessions didn't improve significantly. Our result also disagrees with Sachdev et al. study as there was decrease in Y-BOCS by $57 \%$ on the right side and $27 \%$ on the left side (p $<.01$ ). However, the absence of sham group did not exclude the possibility of the placebo effect as after correcting the depression scores on the MADRS that significance disappeared $(\mathrm{P}=0.06) .{ }^{18}$
In our study although there were no statistical significant differences between the active and the sham groups, patients treated with active rTMS had a somewhat greater reduction in OCD symptoms.

The negative results that we have obtained may be related to many limitations such; the short stimulation period (two weeks), dependence on the manual targeting $(5 \mathrm{~cm}$ rule) in coil localization, relying on the tilting method in sham stimulation, relatively small sample size, the nature of the target group whom resistant OCD patients and finally choosing Rt- DLPFC as the target region for stimulation which is only one of the neural circuits involved in the occurrence of OCD symptoms, or a starting point to induce remote stimulation of other circuits also involved in OCD and persistence of symptoms, such as OFC and SMA which can't be stimulated directly using rTMS techniques used in the present study.

So we recommend that; Conducting more studies involving larger numbers of patients with a less chronic form of OCD, taking into account that there are other regions involved in the occurrence of OCD, the impact of psychiatric drugs, neuroimaging and computer modeling of TMS to determine optimal stimulation targets and the change in brain activity in OCD during rest than exposure to stimuli.

\section{CONCLUSION}

The two-week treatment with rTMS applied over the Rt-DLPFC as an adjunctive treatment does not outweigh the sham stimulation in relieving OCD symptoms, reducing clinical severity or improving treatment response. However, it has a role in improving symptoms of associated depressive symptoms, especially with active LF-rTMS.

\section{REFERENCES}

1. American Psychiatric Association. Diagnostic and statistical manual of mental disorders: DSM-5. Washington, D.C: American Psychiatric Association; 2013.

2. Goodman WK, Grice DE, Lapidus KA, Coffey BJ. Obsessive compulsive disorder. Psychiatr Clin North Am 2014; 37 (3):257-67.

3. Ruscio A, Stein D, Chiu W, Kessler R. The epidemiology of obsessive-compulsive disorder in the national comorbidity survey replication. $\mathrm{Mol}$ Psychiatry. 2010; 15(1):53-63.

4. Stein DJ, Koen N, Fineberg N, Fontenelle LF, Matsunaga H, Osser D, et al. A 2012 evidencebased algorithm for the pharmacotherapy for obsessive-compulsive disorder. Curr Psychiatry Rep 2012; 14:211-219.

5. Abudy A, Juven-Wetzler A, Zohar J. Pharmacological management of treatmentresistant obsessive-compulsive disorder. CNS Drugs 2011; 25:585-596. 
6. Rehn S, Eslick GD, Brakoulias V. A meta-analysis of the effectiveness of different cortical targets used in repetitive transcranial magnetic stimulation (rTMS) for the treatment of obsessive-compulsive disorder (OCD) Psychiatr Q.2018; 89:645-65.

7. Elbeh KA, Elserogy YM, Khalifa HE, Ahmed MA, HafezMH, Khedr EM. Repetitive transcranial magnetic stimulation in the treatment of obsessivecompulsive disorders: double blind randomized clinical trial.Psychiatry Res. 2016; 238:264-9.

8. Shayganfard M, Jahangard L, Nazaribadie M, Haghighi M, Ahmadpanah M, Sadeghi Bahmani $\mathrm{D}$, et al. Repetitive Transcranial Magnetic Stimulation Improved Symptoms of ObsessiveCompulsive Disorders but Not Executive Functions: Results from a Randomized Clinical Trial with Crossover Design and Sham Condition. Neuropsychobiology 2016; 74(2):115-24.

9. Seo HJ, Jung YE, Lim HK, Um YH, Lee CU, Chae JH. Adjunctive low-frequency repetitive transcranial magnetic stimulation over the right dorsolateral prefrontal cortex in patients with treatment-resistant obsessive-compulsive disorder: a randomized controlled trial. Clinical Psychopharmacology and Neuroscience. 2016; 14(2):153-60.

10. Nuno Sousa and Ricardo Moreira. Efficacy of transcranial magnetic stimulation in the treatment of Obsessive-compulsive disorder. International Journal of Clinical Neurosciences and Mental Health 2018; 5:5.

11. Goodman WK, Price LH, Rasmussen SA, Mazure C, Fleischmann RL, Hill CL, et al. The YaleBrown Obsessive Compulsive Scale. I. Development, use, and reliability. Arch Gen Psychiatry 1989; 46:1006-1011.

12. Hamilton M. The assessment of anxiety states by rating. Br J Med Psychol 1959; 32:50-55.

13. Beck AT, Steer RA, Brown GK. BDI-II. Beck depression inventory. 2nd ed. San Antonio, TX:Psychological Corporation; 1996.

14. Guy W. ECDEU assessment manual for psychopharmacology, revised. Rockville, MD:National Institute of Mental Health;1976.

15. Shivakumar V, Dinakaran D, Narayanaswamy JC, Venkatasubramanian G. Noninvasive brain stimulation in obsessive-compulsive disorder. Indian J Psychiatry 2019; 61, Suppl S1:66-76.

16. Ana Lusicic, Koen RJ Schruers, Stefano Pallanti,and David J. Castle. Transcranial magnetic stimulation in the treatment of obsessivecompulsive disorder: current perspectives. Neuropsychiatric Dis Treat. 2018; 14: 1721-1736.

17. Mansur CG, Myczkowki ML, Cabral SD, Sartorelli MDB, Bellini BB, Dias AM, et al. Placebo effect after prefrontal magnetic stimulation in the treatment of resistant obsessivecompulsive disorder: a randomized controlled trial. Int J Neuropsychopharmacol. 2011; 14(10):138997.
18. Sarkhel S, Sinha VK, Praharaj SK. Adjunctive high-frequency right prefrontal repetitive transcranial magnetic stimulation (rTMS) was not effective in obsessive-compulsive disorder but improved secondary depression. J Anxiety Disord. 2010; 24(5):535-9.

19. Pallanti S, Hollander E, Bienstock C, Koran L, Leckman J, Marazziti D, et al. Treatment nonresponse in OCD: methodologicalissues and operational definitions. Int J Neuropsychopharmacol 2002; 5(2):181 91. 